\title{
Technical note: Development and validation of a method using ultra performance liquid chromatography coupled with tandem mass spectrometry for determination of vitamin $B_{12}$ concentrations in milk and dairy products
}

\author{
E. Zironi, T. Gazzotti, A. Barbarossa, C. Devicienti, M. Scardilli, and G. Pagliuca ${ }^{1}$ \\ Laboratory of Analytical Bio-Agroalimentary Chemistry (CABA-Lab), Department of Veterinary Medical Sciences, \\ Alma Mater Studiorum - University of Bologna, Via Tolara di Sopra 50, 40064 Ozzano Emilia (BO), Italy
}

\begin{abstract}
A method using ultra performance liquid chromatography coupled with tandem mass spectrometry was developed to measure cobalamins in naturally enriched raw milk and to evaluate their fate during thermal treatments and along the process of cheese making. After addition of methotrexate as internal standard, samples were submitted to heat treatment in the presence of cyanide, which converts all the less-stable cobalamins into cyanocobalamin; then, purification was performed by a solid-phase extraction step. Reverse-phase ultra performance liquid chromatography separation coupled with tandem mass spectrometry provided a fast and reliable determination. Mass spectrometric analysis was carried out in multiple reaction monitoring mode. The monitored transitions were $\mathrm{m} / z 678.36 \rightarrow 147.10$ and $678.36 \rightarrow 359.30$ for vitamin $\mathrm{B}_{12}$ and $\mathrm{m} / z 455.22 \rightarrow$ 175.13 and $455.22 \rightarrow 308.22$ for methotrexate (internal standard). The limit of quantification was $2 \mathrm{ng} / \mathrm{g}$. The method showed good linearity from 2 to $20 \mathrm{ng} / \mathrm{g}\left(\mathrm{R}^{2}\right.$ $\geq 0.98$ ) and intra- and interday precisions were always less than $19 \%$.
\end{abstract}

Key words: milk, dairy product, vitamin $\mathrm{B}_{12}$, liquid chromatography-mass spectrometry

\section{Technical Note}

Vitamin $\mathrm{B}_{12}$, or cobalamin, is a water-soluble vitamin containing cobalt as the central ion in a corrin ring; vitamin $\mathrm{B}_{12}$ plays an important role in nutrition, being fundamental for the correct formation of red blood cells and maintaining a healthy myelin sheath of nerve cells (Kumar et al., 2010). Therefore, vitamin $\mathrm{B}_{12}$ deficiency may lead in humans to anemia and neurological dysfunctions.

The daily requirement of vitamin $\mathrm{B}_{12}$ is about 1 to 2 $\mu \mathrm{g}$ (Chassaigne and Łobiński, 1998); the main source of

Received December 4, 2012.

Accepted January 12, 2013.

${ }^{1}$ Corresponding author: giampiero.pagliuca@unibo.it vitamin $\mathrm{B}_{12}$ is food of animal origin, and milk and dairy products provide a significant dietary intake (Marley et al., 2009). The main natural forms of cobalamin present in food are hydroxocobalamin, 5'-deoxyadenosylcobalamin, methylcobalamin, and cyanocobalamin, which occurs only in small amounts. Cyanocobalamin is more stable than the other forms that are light sensitive (Eitenmiller et al., 2007). In milk and dairy products, cobalamins are protein bound (Fie et al., 1994); this can partially protect them, but represents a challenge for analytical determination.

In addition, vitamin $B_{12}$ is generally present in food in quite low concentrations, making its quantification difficult. The most-used methods, also recommended by AOAC International (Gaithersburg, MD), are microbiologic tests that use Lactobacillus delbrueckii (Eitenmiller et al., 2007; Wyk and Britz, 2010). These methods were originally developed for the analysis of vitamin preparations, but afterward have also been applied to fortified foods and to food matrices in general.

Several studies on chemical quantification of vitamin $\mathrm{B}_{12}$ in different matrices have been reported in the literature; most of them are radioisotopic assays (Indyk et al., 2002; Arkbåge et al., 2003) or are methods based on chromatographic techniques combined with UV (Heudi et al., 2006; Campos-Giménez et al., 2008; Lu et al., 2008; Marley et al., 2009), fluorescence (Pakin et al., 2005), or diode array (Viñas et al., 2003) detectors. However, due to their poor sensitivity, these methods are suitable for fortified food analyses but not for natural matrix determinations. More recently, some HPLC-electrospray ionization (ESI)-mass spectrometry methods have been developed for determination of vitamin $\mathrm{B}_{12}$ concentrations in food products (Luo et al., 2006; Lu et al., 2008; Szterk et al., 2012); the use of more sensitive and selective techniques, such as tandem mass spectrometry, allows the determination of naturally occurring cobalamin in food at trace levels. The aim of the present work was to develop and validate a sensitive method for vitamin $\mathrm{B}_{12}$ determination in milk and dairy products using ultra performance liquid chromatography coupled with tandem mass spectrometry. 
Table 1. Multiple reaction monitoring mode transition monitored for each compound

\begin{tabular}{lccc}
\hline Compound & $\begin{array}{c}\text { Transition } \\
(\mathrm{m} / z)\end{array}$ & $\begin{array}{c}\text { Cone voltage } \\
(\mathrm{V})\end{array}$ & $\begin{array}{c}\text { Collision } \\
\text { energy }(\mathrm{eV})\end{array}$ \\
\hline Vitamin $\mathrm{B}_{12}$ & $678.36 \rightarrow 147.10$ & 35 & 43 \\
Methotrexate (internal standard) & $678.36 \rightarrow 359.30$ & 35 & 23 \\
& $455.22 \rightarrow 175.13$ & 30 & 39 \\
& $455.22 \rightarrow 308.22$ & 30 & 19 \\
\hline
\end{tabular}

Vitamin $\mathrm{B}_{12}$ and methotrexate (internal standard, IS) standards were purchased from Sigma-Aldrich Chemical Co. (St. Louis, MO). Sodium acetate trihydrate, formic acid, and acetonitrile were Fluka reagents of mass spectrometry grade (Sigma-Aldrich Chemical Co.). Potassium cyanide (Carlo Erba Reagenti SpA, Rodano, Italy) and glacial acetic acid (Merck KGaA, Darmstadt, Germany) were of analytical grade. Ultrapure water was produced in house via a Human Power water purification system (Human Corp., Seoul, Korea). The solid-phase extraction (SPE) cartridges were Oasis HLB 500 mg/6 cc cartridges (Waters Corp., Milford, MA).

The 2 stock solutions of vitamin $\mathrm{B}_{12}$ and methotrexate (IS) were prepared by dissolving $10 \mathrm{mg}$ of standard in $100 \mathrm{~mL}$ of water, and they were kept refrigerated at $4^{\circ} \mathrm{C}$. The working solutions of both standards were obtained by diluting the stock solution in water to a final concentration of $1 \mu \mathrm{g} / \mathrm{mL}$.

The calibration curve was prepared spiking $5 \mathrm{~g}$ of blank skimmed raw milk with appropriate amounts of the vitamin $\mathrm{B}_{12}$ standard working solution to obtain 6 levels of concentration $(2,4,6,8,10$, and $20 \mathrm{ng} / \mathrm{g})$; $30 \mu \mathrm{L}$ of the internal standard methotrexate working solution was also added to each sample.

Quality control (QC) samples were prepared spiking $5 \mathrm{~g}$ of blank skimmed raw milk with appropriate amounts of the vitamin $\mathrm{B}_{12}$ standard working solution to obtain concentrations of 3,5 , and $7 \mathrm{ng} / \mathrm{g}$ and a fixed amount $(30 \mu \mathrm{L})$ of methotrexate (IS) working solution. All the QC samples were prepared in triplicate each validation day. Eight blank (not spiked) samples were freshly prepared each validation day (3 d) and injected at least twice for each running batch.

Ten grams of raw milk was centrifuged at 4,000 $\times g$ for $10 \mathrm{~min}$ at $4^{\circ} \mathrm{C}$ to separate and eliminate the fat. The extraction procedure was conducted on $5 \mathrm{~g}$ of skim milk with the addition of $5 \mathrm{~mL}$ of aqueous sodium acetate buffer $(200 \mathrm{~m} M$, adjusted to $\mathrm{pH} 4$ with glacial acetic acid) and $150 \mu \mathrm{L}$ of a $1 \%$ potassium cyanide solution in water; $30 \mu \mathrm{L}$ of methotrexate was also added as IS for quantification (Lu et al., 2008).

The sample was then heated to $90^{\circ} \mathrm{C}$ for an hour; the presence of cyanide in the extraction buffer is critically important to ensure quantitative conversion of all forms of vitamin $B_{12}$ to cyanocobalamin, the most stable form of the vitamin, whereas the heat treatment liberates all protein-bound cobalamins (Luo et al., 2006).

After cooling, samples were purified by a single SPE step: the cartridge was previously conditioned with 2 $\mathrm{mL}$ of acetonitrile and equilibrated with $2 \mathrm{~mL}$ of water; then, the sample was loaded, washed with $2 \mathrm{~mL}$ of water, and eluted with $1 \mathrm{~mL}$ of an acetonitrile:water (1:1) solution. Ten milliliters of sample was analyzed by liquid chromatography coupled with tandem mass spectrometry in positive ESI mode.

The separation was performed by an Acquity ultraperformance liquid chromatographic system, consisting of a binary pump, solvent degasser, autosampler, and column heater fitted with a Waters HSS T3 column $(1.7-\mu \mathrm{m}$ film thickness, $2.1 \times 50 \mathrm{~mm})$ equipped with a guard column with the same packing (Waters Corp.).

The flow rate was $0.3 \mathrm{~mL} / \mathrm{min}$ and the column temperature was kept at $45^{\circ} \mathrm{C}$. Separation was carried out

Table 2. Accuracy data

\begin{tabular}{llrrrr}
\hline $\begin{array}{l}\text { Fortification } \\
\text { level }\end{array}$ & Measurement & d 1 & d 2 & d 3 & $\begin{array}{c}\text { Interday } \\
(\mathrm{n}=9)\end{array}$ \\
\hline $3 \mathrm{ng} / \mathrm{g}$ & Mean (n = 3) & 3.4 & 3.1 & 2.7 & 3.1 \\
& Precision (CV, \%) & 7.8 & 18.4 & 3.4 & 14.0 \\
$5 \mathrm{ng} / \mathrm{g}$ & Trueness (Bias, \%) & 12.2 & 3.3 & -8.9 & 2.2 \\
& Mean (n = 3) & 5.6 & 4.8 & 5.1 & 5.2 \\
& Precision (CV, \%) & 1.7 & 10.2 & 11.7 & 10.0 \\
$7 \mathrm{ng} / \mathrm{g}$ & Trueness (Bias, \%) & 11.3 & -3.3 & 2.7 & 3.6 \\
& Mean (n = 3) & 7.4 & 8.8 & 6.3 & 7.5 \\
& Precision (CV, \%) & 7.5 & 5.7 & 4.7 & 14.8 \\
& Trueness (Bias, \%) & 6.2 & 25.7 & -10.0 & 7.3 \\
\hline
\end{tabular}


ZIRONI ET AL.
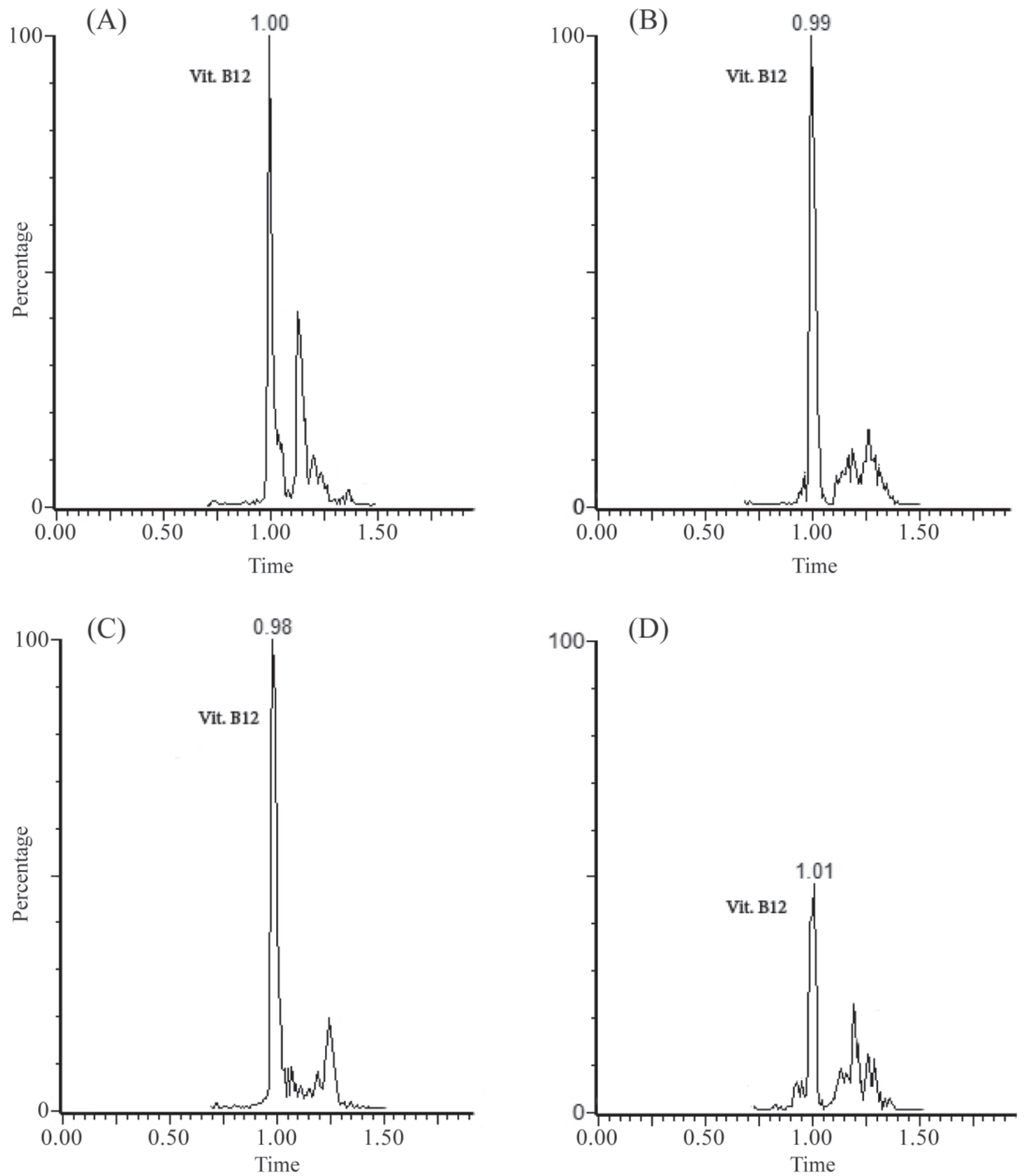

Figure 1. Chromatogram of a milk sample fortified at $2 \mathrm{ng} / \mathrm{g}(\mathrm{A})$, of Caciotta cheese (B), serum (C), and curd (D) samples. Vit. B12 = vitamin $\mathrm{B}_{12}$. 
in programmed condition with mobile phase consisting of water (A) and acetonitrile containing $0.1 \%$ formic acid (B), for a total run time of $5 \mathrm{~min}$. The gradient was as follows: $\mathrm{T}_{0} \min : 90 \% \mathrm{~A}, 10 \% \mathrm{~B} ; \mathrm{T}_{2} \min : 20 \% \mathrm{~A}$, $80 \% \mathrm{~B}$; and $\mathrm{T}_{3} \mathrm{~min}$ to the end: $90 \% \mathrm{~A}, 10 \% \mathrm{~B}$.

The mass spectrometer was a Quattro Premiere XE, a triple quadrupole instrument equipped with an ESCI multi-mode ionization source (Waters Corp.). All the analyses were conducted in positive ESI mode using selected reaction monitoring set on the 2 main product ions; the optimized mass spectrometer conditions for both analytes are reported in Table 1 . The capillary voltage was $3.2 \mathrm{kV}$, source temperature $120^{\circ} \mathrm{C}$, and desolvation temperature $350^{\circ} \mathrm{C}$. Nitrogen was used as desolvation gas $(750 \mathrm{~L} / \mathrm{h})$ and cone gas $(200 \mathrm{~L} / \mathrm{h})$, whereas the collision gas was argon (flow rate of 0.35 $\mathrm{mL} / \mathrm{min}$ ). Data acquisition processing was performed using Mass Lynx 4.1 software (Waters Corp.).

The analytical validation of the method was conducted on fortified milk samples. Because vitamin $\mathrm{B}_{12}$ naturally occurs in milk, it was not possible to find a blank matrix. Therefore, the performance of the method was evaluated using the standard addition method.

Accuracy (trueness and precision) was estimated by analyzing fortified samples at 3 different levels: 3, 5, and $7 \mathrm{ng} / \mathrm{g}$ (QC samples). These samples were freshly prepared in triplicate each validation day $(3 \mathrm{~d})$ and injected at least twice for each running batch.

Trueness, determined as bias (\%), was assessed by correlating the estimated amounts with the nominal concentrations, whereas precision was expressed as coefficient of variation. The validation results are summarized in Table 2.

The specificity of the method could be demonstrated by analysis of milk and milk fortified samples. In these latter, the chromatograms showed a significant increase in peak area intensity at the specific retention time of the compound (Figure 1).

Linearity was assessed on 6 concentration levels, over the range from 2 to $20 \mathrm{ng} / \mathrm{g}$; matrix calibration standard curves were freshly prepared on each validation day (3 d) and injected at least 3 times for each running batch. The regression lines obtained were all satisfactory with a coefficient of determination $\left(\mathrm{R}^{2}\right)$ always higher than 0.98. The limit of quantification, corresponding to the lowest point of the calibration curve, was $2 \mathrm{ng} / \mathrm{g}$.

The method was successfully applied to samples of raw milk; some dairy products such as Mozzarella cheese, Ricotta cheese, and Caciotta cheese; and other intermediate products of cheese making, such as serum and curd. The vitamin $\mathrm{B}_{12}$ values obtained in raw milk samples were within the range of 2 to $8 \mathrm{ng} / \mathrm{g}$, confirming the natural level reported in the literature (Fie et al., 1994). For solid matrices it has been necessary to use a centrifugation step $(4,000 \times g$ for $10 \mathrm{~min})$ before SPE cleanup, to have a better separation between the liquid phase and the solid residue. The effects of this additional step on recoveries were investigated and the results confirmed that it does not affect the method performances.

The complexity of vitamin $\mathrm{B}_{12}$ quantification in food matrices has been investigated by several authors, but very little work has been done to quantify $\mathrm{B}_{12}$ in milk, and in particular on dairy products by mass spectrometry. The proposed method combines the rapidity and high resolution of ultra performance liquid chromatography coupled with tandem mass spectrometry. Moreover, sample preparation is not based on immunoaffinity extraction but only requires a simple SPE purification step. Performance was satisfactory in terms of selectivity, sensitivity, and accuracy, making the current method a useful tool to quantify vitamin $\mathrm{B}_{12}$ in milk and dairy products and to test possible zootechnical strategies aimed at obtaining milk with higher vitamin $\mathrm{B}_{12}$ content or at studying the effects of heat treatments and transformation processes on cobalamin.

\section{ACKNOWLEDGMENTS}

This project was financed by the Italian Ministero delle Politiche Agricole Alimentari e Forestali (Rome, Italy) in the frame of the "BIOVITA" project.

\section{REFERENCES}

Arkbåge, K., C. Witthöft, R. Fondén, and M. Jägerstad. 2003. Retention of vitamin $\mathrm{B}_{12}$ during manufacture of six fermented dairy products using a validated radio protein-binding assay. Int. Dairy J. 13:101-109.

Campos-Giménez, E., P. Fontannaz, M. J. Trisconi, T. Kilinç, C. Gimenez, and P. Andrieux. 2008. Determination of vitamin $\mathrm{B}_{12}$ in food products by liquid chromatography/UV detection with immunoaffinity extraction: Single-laboratory validation. J. AOAC Int. 91:786-793.

Chassaigne, H., and R. Łobiński. 1998. Direct species-selective determination of cobalamins by ionspray mass spectrometry and ionspray tandem mass spectrometry. Analyst (Lond.) 123:131-137.

Eitenmiller, R. R., L. Ye, and W. O. Landen Jr. 2007. Chapter 11: Vitamin $\mathrm{B}_{12}$. Pages 507-534 in Vitamin Analysis for the Health and Food Sciences. CRC Press, Boca Raton, FL.

Fie, M., J. A. Zee, and J. Amiot. 1994. Effet des traitements thermiques sur la mise en disponibilité de la vitamine $\mathrm{B}_{12}$ dans le lait. Lait 74:461-472.

Heudi, O., T. Kilinç, P. Fontannaz, and E. Marley. 2006. Determination of vitamin $\mathrm{B}_{12}$ in food products and in premixes by reversedphase high performance liquid chromatography and immunoaffinity extraction. J. Chromatogr. A 1101:63-68.

Indyk, H. E., B. S. Persson, C. B. Caselunghe, A. Moberg, E. L. Filonzi, and D. C. Woollard. 2002. Determination of vitamin B12 in milk products and selected foods by optical biosensor proteinbinding assay: Method comparison. J. AOAC Int. 85:72-81.

Kumar, S. S., R. S. Chouhan, and M. S. Thakur. 2010. Trends in analysis of vitamin $\mathrm{B}_{12}$. Anal. Biochem. 398:139-149.

Lu, B., Y. Ren, B. Huang, W. Liao, Z. Cai, and X. Tie. 2008. Simultaneous determination of four water-soluble vitamins in fortified 
infant foods by ultra-performance liquid chromatography coupled with triple quadrupole mass spectrometry. J. Chromatogr. Sci. 46:225-232.

Luo, X., B. Chen, L. Ding, F. Tang, and S. Yao. 2006. HPLC-ESI-MS analysis of vitamin B12 in food products and in multivitaminsmultimineral tablets. Anal. Chim. Acta 562:185-189.

Marley, E. C., E. Mackay, and G. Young. 2009. Characterisation of vitamin B12 immunoaffinity columns and method development for determination of vitamin B12 in a range of foods, juices and pharmaceutical products using immunoaffinity clean-up and high performance liquid chromatography with UV detection. Food Addit. Contam. Part A Chem. Anal. Control Expo. Risk Assess. $26: 282-288$.

Pakin, C., M. Bergaentzlé, D. Aoudé-Werner, and C. Hasselmann. 2005. $\alpha$-Ribazole, a fluorescent marker for the liquid chromato- graphic determination of vitamin $\mathrm{B}_{12}$ in foodstuffs. J. Chromatogr. A 1081:182-189.

Szterk, A., M. Roszko, K. Małek, M. Czerwonka, and B. Waszkiewicz-Robak. 2012. Application of the SPE reversed phase HPLC/ MS technique to determine vitamin B12 bio-active forms in beef. Meat Sci. 91:408-413.

Viñas, P., C. López-Erroz, N. Balslobre, and M. Hernández-Córdoba 2003. Speciation of cobalamins in biological samples using liquid chromatography with diode-array detection. Chromatographia 58:5-10.

Van Wyk, J., and T. J. Britz. 2010. A rapid HPLC method for the extraction and quantification of vitamin $\mathrm{B}_{12}$ in dairy products and cultures of Propionibacterium freudenreichii. Dairy Sci. Technol. 90:509-520. http://dx.doi.org/10.1051/dst/2009055. 